\title{
Is thoracic facet joint arthritis over-reported? It's time to review CT grading parameters - An analytical cross-sectional study
}

\begin{abstract}
Punit Tiwari, Harmeet Kaur ${ }^{1}$, Vivek Jha
Department of Orthopaedics, Maharishi Markandeshwar Medical College and Hospital, Solan, Himachal Pradesh, 'Department of Radiodiagnosis, All India Institute of Medical Sciences, Bathinda, Punjab, India

Correspondence: Dr. Harmeet Kaur, Department of Radiodiagnosis, All India Institute of Medical Sciences, Bathinda, Punjab, India. E-mail: kaurh28@yahoo.com
\end{abstract}

\begin{abstract}
Background: In the absence of any exclusive classification for dorsal FJA, there is a lot of confusion while labelling grade $1 \mathrm{FJA}$ in thoracic spine based on decreased FJ space. Purpose: The purpose of this study was to know the facet joint space measurements in thoracic spine of asymptomatic and symptomatic participants and to comment whether the lower cut-off of $2 \mathrm{~mm}$ used in lumbar FJA classification can be safely applied in thoracic spine too. Materials and Methods: This cross-sectional study was done from December 1, 2018 to November 30, 2019. Patients above 18 years of age in this study who underwent CT thorax for causes unrelated to dorsal spinal pain were included. IBM SPSS Statistics $v 26$ was used for statistical analysis. Results: We measured and analysed 1512 thoracic facet joints in 63 patients (30 females and 33 males) in both axial and sagittal plane on CT scan. Mean age of the entire sample was $59.19 \pm 15.19$ years, ranging from 33 to 97 years and a standard error of mean 1.365 years. Overall mean thoracic facet joint space was measured to be $1.270 \mathrm{~mm} \pm 0.3416 \mathrm{~mm}$, ranging from 0 to $3.1 \mathrm{~mm}$ and a standard error of mean $0.0088 \mathrm{~mm}$ and a variance of $0.117 \mathrm{~mm}$. The median was $1.300 \mathrm{~mm}$ while mode was $1.1 \mathrm{~mm}$. Conclusion: The popular lumbar FJA classification by Weishupt et al. cannot be applied in its present form in thoracic spine, without the modification in parameters of grade $1 \mathrm{FJA}$. The lower cut-off of normal thoracic facet joint space probably lies around $1 \mathrm{~mm}$.

MeSH Terms: Zygapophyseal joints, dorsal, thoracic, facet joint, arthritis, classification
\end{abstract}

Key words: Dorsal; facet joint arthritis; facet joint space; measurements; thoracic; width

\section{Introduction}

Radiologists are often provided with little or no relevant clinical history while reporting CT (Computed Tomography) scans or MRI (Magnetic Resonance Imaging) of the patients with chronic or non-specific spine pain. In the absence of any

\begin{tabular}{|l|l|}
\hline \multicolumn{2}{|c|}{ Access this article online } \\
\cline { 1 - 2 } Quick Response Code: & Website: \\
\cline { 1 - 2 } & www.ijri.org \\
\hline & DOI: \\
\cline { 1 - 2 } & 10.4103/ijri.IJRI_390_20 \\
\hline
\end{tabular}

definitive findings on imaging, which can possibly explain the pain and discomfort of the patient, the sensitivity of the radiologist increases even to the trivial changes in the spine. Radiology report does influence the decision making in this

This is an open access journal, and articles are distributed under the terms of the Creative Commons Attribution-Non Commercial-Share Alike 4.0 License, which allows others to remix, tweak, and build upon the work non-commercially, as long as appropriate credit is given and the new creations are licensed under the identical terms.

For reprints contact: WKHLRPMedknow_reprints@wolterskluwer.com

Cite this article as: Tiwari $\mathrm{P}, \mathrm{Kaur} \mathrm{H}$, Jha V. Is thoracic facet joint arthritis over-reported? It's time to review CT grading parameters - An analytical cross-sectional study. Indian J Radiol Imaging 2020;30:427-35.

Received: 19-May-2020 Accepted: 01-Sep-2020

Revised: 12-Jul-2020 Published: 13-Jan-2021 
time of evidence based medicine. Not only the regulatory agencies but the current literature has also started raising concerns that are we over-reporting in spine? ${ }^{[1-3]}$

Currently, the classification system of lumbar facet joint arthritis, published by Weishupt et al..$^{\left[{ }^{[4]} \text { in }\right.} 1999$ is very popular and used as a reference for thoracic facet joint arthritis too. It is adapted and modified from the initial classification by Pathria et al. ${ }^{[5]}$ proposed in 1987.

Thoracic and lumbar vertebrae are different not only anatomically but they also have different biomechanical functions as well as constraints. In thoracic vertebrae the superior articular processes bear facets that face backward and laterally, while the facets on the inferior articular processes face forward and medially. Whereas, in lumbar vertebrae the articular surfaces of the superior articular processes face medially, and those of the inferior articular processes face laterally ${ }^{[6]}$ The opposing bony surfaces are covered by hyaline articular cartilage, and the joint is encapsulated by the synovium and fibrous capsule.

Though the prevalence of thoracic backache is less as compared to lumbar region still it is of significant importance..$^{[7-13]}$

To the best of our knowledge any specific classification for assessing the thoracic facet joint arthritis is not available in literature till date. No guidelines are available in standard radio-diagnosis text books regarding the normal width measurements of thoracic facet joints.

It is a common problem faced by musculoskeletal radiologists while routine $\mathrm{CT}$ and MRI reporting that whether to label the thoracic joints as grade 1 arthritic when the space looks narrow as compared to lumbar facet joints but other tell-tale signs of degeneration are missing.

\section{Purpose}

In this paper, we have attempted to answer these two questions:

1. What are the measurements of thoracic facet joint space in symptomatic and asymptomatic study population?

2. Can the lower cut off of $2 \mathrm{~mm}$ for labelling Facet Joint Arthritis be safely applied to thoracic facet joints?

What is the hurdle in delimiting the normal and arthritic facet joint space in dorsal spine?

As per the standard protocol, the values of thoracic facet joint spaces ought to be compared in the control and case i.e., FJA group. Further, the validity of the facet joint space for the diagnosis of thoracic facet joint arthritis should be estimated by plotting the receiver operating characteristic (ROC) curve and determining the area under the curve (AUC) along-with sensitivity and specificity of cut-off points.
The problem lies in defining the 'case'. There is no 'gold standard' definition of facet joint arthritis. It is not possible to accurately diagnose the facet joint pain either by physical examination ${ }^{[14]}$ or by imaging. ${ }^{[15]}$ There is only moderate co-relation between radiologic and pathologic grading of facet joints. ${ }^{[16]}$ Significant numbers of clinically asymptomatic but radiologically arthritic facet joints makes the situation further complex. ${ }^{[17,18]}$ Even the diagnostic blocks have significant false positive results. ${ }^{[19,20]}$

\section{Methodology}

The cross-sectional study was carried out after taking approval from ethical committee of our institution in a Medical College setting from December 1, 2018 to November 30, 2019. We analysed the CT scans of 63 patients (1512 thoracic facet joints) in this time period who gave us informed consent. A 128 slice computed tomography scanner by Philips Medical System (Model no: Ingenuity Core 128) was used to analyse facet joints of both sides in both axial as well as sagittal planes in bone window. Negative/reverse mode of the images was also used in some participants to measure thoracic facet joint widths using window adjustment setting wherever required. The axial slice thickness of $1 \mathrm{~mm}$ was used in thoracic imaging.

We included participants above 18 years of age in this study who underwent CT thorax for cause sun related to dorsal spinal pain. Participants with a history of spine trauma or metastasis/tumours or tuberculosis of spine or not in condition to give history were excluded from the study. The measurements of facet joint space was done by a single person, the second author herself and she was not aware of the response of patient to the question of thoracic spine pain. The individuals' answer to the question 'Have you had spinal pain in the scanned part for past 12 months?' was used in the present study as the spinal pain outcome. This was asked by trained post graduate students. The individuals who report edhaving pain on 'all days' or 'most of the days' were considered to be symptomatic, and individuals who reported having no spinal pain, spinal pain on 'a few days', or 'some days' were considered to be asymptomatic. Those who helped in data collection were not involved in CT analysis.

IBM SPSS Statistics v 26 was used for statistical analysis. Descriptive statistics (Means, Standard deviation, Standard error of mean, Variance etc.) was run for the entire sample, those considered symptomatic as well as those considered asymptomatic. All data generated or analysed during the study are included in the published paper.

Most of the data collected followed non normal distribution (tested using Kolmogorov-smirnova and Shapiro-wilke test).Comparison between groups was 
done using non parametric tests vizKruskalwallis, Mann Whitney $U$ test where appropriate. Bivariate pearson correlation was used to evaluate correlation between age and facet joint measurements. Chi square test was used for correlation of categorical parameters. Box plots and graphs were created accordingly from the collected data for visual representation.

\section{Results}

A total of 63 participants were enrolled in the study[Table 1] and a total of 1512 thoracic facet joints were measured across all levels. Mean age of the entire study sample was $59.19 \pm 15.19$ years, ranging from 33-97 years and a standard error of mean 1.365 years. Overall mean thoracic facet joint space was measured to be $1.270 \mathrm{~mm} \pm 0.3416 \mathrm{~mm}$, ranging from 0 to $3.1 \mathrm{~mm}$ and a standard error of mean $0.0088 \mathrm{~mm}$ and a variance of $0.117 \mathrm{~mm}$. The median was $1.300 \mathrm{~mm}$ while mode was $1.1 \mathrm{~mm}$.[Figure 1] shows box plot demonstrating distribution of facet joint space in entire sample, including outliers. As can be noted, lower quartile $\left(25^{\text {th }}\right.$ percentile) was $1.1 \mathrm{~mm}$ and upper quartile $\left(75^{\text {th }}\right.$ percentile) was $1.5 \mathrm{~mm}$. Very few thoracic facet joints had spaces more than $2 \mathrm{~mm}$. Means of individual levels of thoracic facet joint space of the overall sample has been outlined in [Table 2] and its distribution has been shown in [Figure 2]. The smallest thoracic facet joint space was noted at $\mathrm{T}_{1-2^{2}}$ closely followed by $\mathrm{T}_{4-5^{\prime}}$ while $\mathrm{T}_{10-11}$ recorded largest facet joint space. $\mathrm{T}_{11-12}$ and $\mathrm{T}_{12}-\mathrm{L}_{1}$ facet joint spaces were recorded less than $\mathrm{T}_{10-11}$. [Figure 3 ] shows the trend of thoracic facet joint space from $T_{1-2}$ to $T_{12}-L_{1}$. When thoracic facet joints were sub-classified as upper ( $\mathrm{T}_{1-2}$ to $\left.\mathrm{T}_{4-5}\right)$, Middle $\left(\mathrm{T}_{5-6}\right.$ to $\left.\mathrm{T}_{8-9}\right)$ and lower $\left(\mathrm{T}_{12}-\mathrm{L}_{1}\right)$, there was

Table 1: Demography of the study population

\begin{tabular}{lcccc}
\hline & & $\begin{array}{c}\text { Females } \\
\text { Number }(\%)\end{array}$ & $\begin{array}{c}\text { Males } \\
\text { Number }(\%)\end{array}$ & $\begin{array}{c}\text { Total } \\
\text { Number }(\%)\end{array}$ \\
\hline Population & & $30(47.6 \%)$ & $33(52.4 \%)$ & $63(100 \%)$ \\
Spine pain & No & 9 & 18 & $27(42.9 \%)$ \\
& Yes & 21 & 15 & $36(57.1 \%)$ \\
Age & $<40$ years & 3 & 0 & $3(4.8 \%)$ \\
& $40-49$ & 7 & 9 & $16(25.4 \%)$ \\
& $50-59$ & 11 & 6 & $17(27 \%)$ \\
& $60-69$ & 3 & 3 & $6(9.5 \%)$ \\
& $\geq 70$ & 6 & 15 & $21(33.3 \%)$ \\
\hline
\end{tabular}

a steady increase in mean of facet joint space from upper to lower. [Figure 4] Significant difference was present between the three subgroups of thoracic facet joints based on location - Kruskallwallis test between groups: $P=0.000$.

33 men and 30 women were present in the study. Men had significantly larger mean facet joint measurements as compared to women $(P=0.001, \mathrm{z}=-3.267$; Mann Whitney $\mathrm{U}$ test) with a mean difference of $0.1223 \mathrm{~mm}$. [Table 3] compares means of facet joint space at individual levels in men and women.

In [Table 4]we have outlined the percentage of study population that would be classified as having FJA if we consider the individual cut offs.

A total of 27 participants were asymptomatic (18men, 9 women). The mean age of asymptomatic sample was 64.85 years \pm 15.84 years. Standard error of mean was 2.156 years and median age was 62 years. Age of participants ranged from 43 to 97 years. A total of 648 thoracic facet joints were measured across all levels in them.

Overall mean thoracic facet joint space in asymptomatic participants was measured to be $1.294 \mathrm{~mm} \pm 0.4146 \mathrm{~mm}$, ranging from 0 to $3.1 \mathrm{~mm}$ and a standard error of mean 0.0163 $\mathrm{mm}$ and a variance of $0.172 \mathrm{~mm}$. The median was $1.300 \mathrm{~mm}$.

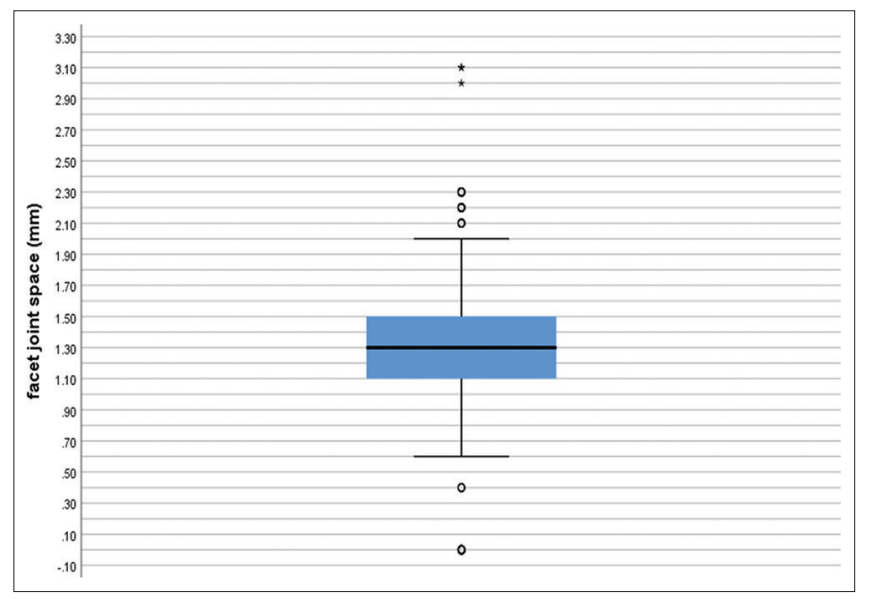

Figure 1: Box plot demonstrating distribution of facet joint space in overall study sample

Table 2: Descriptive data of individual dorsal facet joint space for the overall sample

\begin{tabular}{lcccccccccccc}
\hline & $\mathrm{T}_{1-2}$ & $\mathrm{~T}_{2-3}$ & $\mathrm{~T}_{3-4}$ & $\mathrm{~T}_{4-5}$ & $\mathrm{~T}_{5-6}$ & $\mathrm{~T}_{6-7}$ & $\mathrm{~T}_{7-8}$ & $\mathrm{~T}_{8-9}$ & $\mathrm{~T}_{9-10}$ & $\mathrm{~T}_{10-11}$ & $\mathrm{~T}_{11-12}$ & $\mathrm{~T}_{12}-\mathrm{L}_{1}$ \\
\hline Mean (mm) & 1.163 & 1.226 & 1.190 & 1.169 & 1.276 & 1.294 & 1.329 & 1.316 & 1.337 & 1.378 & 1.290 & 1.271 \\
$\mathrm{SD}(\mathrm{mm})$ & 0.4493 & 0.4753 & 0.3717 & 0.4001 & 0.2572 & 0.2131 & 0.2672 & 0.2741 & 0.3138 & 0.2961 & 0.3214 & 0.2895 \\
$\mathrm{SE}(\mathrm{mm})$ & 0.0400 & 0.0423 & 0.0331 & 0.0356 & 0.0229 & 0.0190 & 0.0238 & 0.0244 & 0.0280 & 0.0264 & 0.0286 & 0.0258 \\
Range (mm) & $0-2.3$ & $0-3.1$ & $0-2.3$ & $0-1.8$ & $0.4-1.8$ & $1.0-1.8$ & $0.9-2.1$ & $0.9-2.1$ & $0.7-2.3$ & $0.7-2.3$ & $0.6-202$ & $0.6-1.9$ \\
$5^{\text {th }}$ percentile (mm) & 1.100 & 1.100 & 1.200 & 1.200 & 1.300 & 1.200 & 1.300 & 1.300 & 1.400 & 1.400 & 1.300 & 1.3 \\
Interquartile range (mm) & 0.3 & 0.3 & 0.4 & 0.3 & 0.3 & 0.3 & 0.4 & 0.4 & 0.4 & 0.3 & 0.4 & 0.4 \\
Variance (mm) & 0.202 & 0.226 & 0.138 & 0.160 & 0.066 & 0.045 & 0.071 & 0.075 & 0.098 & 0.088 & 0.103 & 0.084 \\
\hline
\end{tabular}


Means of facet joint space at individual levels are outlined in [Table 5] and also in [Figure 5] which shows largest facet joint space at $\mathrm{T}_{10-11}$ and smallest at $\mathrm{T}_{4-5}$.

Average facet joint space in males was found to be $1.327 \pm 0.333$ and $1.223 \pm 0.089$ in females. No significant difference was found between the two (Mann Whitney U test $P=0.247)$. Using bivariate Pearson correlation test, significant but negative negligible correlation ${ }^{[21]}$ was found between age and average thoracic facet joint space $(r=-0.276, P=0.044)$ 36 symptomatic participants ( 21 women and 15 men) had mean age 54.96 years \pm 13.53 years. Standard error of mean

Table 3: Comparison of Females and Males

\begin{tabular}{lccc}
\hline & $\begin{array}{c}\text { Females } \\
\text { Mean } \pm \text { SD }\end{array}$ & $\begin{array}{c}\text { Males } \\
\text { Mean } \pm S D\end{array}$ & $\begin{array}{c}\text { Asymp. Sig. (2-tailed) } \\
\text { Mann Whitney } U \text { test }\end{array}$ \\
\hline Age (years) & $53.87 \pm 13.12$ & $64.03 \pm 15.66$ & 0.002 \\
$\mathrm{~T}_{1-2}(\mathrm{~mm})$ & $1.155 \pm 0.4069$ & $1.171 \pm 0.4876$ & 0.727 \\
$\mathrm{~T}_{2-3}(\mathrm{~mm})$ & $1.110 \pm 0.3578$ & $1.332 \pm 0.5427$ & 0.014 \\
$\mathrm{~T}_{3-4}(\mathrm{~mm})$ & $1.105 \pm 0.1952$ & $1.268 \pm 0.4671$ & 0.001 \\
$\mathrm{~T}_{4-5}(\mathrm{~mm})$ & $1.225 \pm 0.2814$ & $1.118 \pm 0.4800$ & 0.824 \\
$\mathrm{~T}_{5-6}(\mathrm{~mm})$ & $1.2700 \pm 0.2367$ & $1.282 \pm 0.2762$ & 0.477 \\
$\mathrm{~T}_{6-7}(\mathrm{~mm})$ & $1.232 \pm 1.905$ & $1.344 \pm 0.2213$ & 0.005 \\
$\mathrm{~T}_{7-8}(\mathrm{~mm})$ & $1.235 \pm 0.1947$ & $1.415 \pm 0.2952$ & 0.001 \\
$\mathrm{~T}_{8-9}(\mathrm{~mm})$ & $1.277 \pm 0.2243$ & $1.352 \pm 0.3100$ & 0.408 \\
$\mathrm{~T}_{9-10}(\mathrm{~mm})$ & $1.203 \pm 0.2577$ & $1.458 \pm 0.3128$ & 0.000 \\
$\mathrm{~T}_{10-11}(\mathrm{~mm})$ & $1.250 \pm 0.2601$ & $1.494 \pm 0.2800$ & 0.000 \\
$\mathrm{~T}_{11-12}(\mathrm{~mm})$ & $1.203 \pm 0.2888$ & $1.370 \pm 0.3310$ & 0.011 \\
$\mathrm{~T}_{12-} \mathrm{L}_{1}(\mathrm{~mm})$ & $1.200 \pm 0.2762$ & $1.336 \pm 0.2880$ & 0.010 \\
Mean all levels $(\mathrm{mm})$ & $1.206 \pm 0.1636$ & $1.328 \pm 0.2518$ & 0.001 \\
\hline
\end{tabular}

Table 4: Percentage of sample that would be classified as having FJA with various cut offs

\begin{tabular}{lcc}
\hline Cut off & $\begin{array}{c}\text { \%of dorsal joints } \\
\text { classified as having FJA }\end{array}$ & $\begin{array}{c}\text { No of dorsal joints } \\
\text { classified as having FJA }\end{array}$ \\
\hline$<2.0 \mathrm{~mm}$ & $97.8 \%$ & 1479 \\
$<1.5 \mathrm{~mm}$ & $71.9 \%$ & 1087 \\
$<1.4 \mathrm{~mm}$ & $61.6 \%$ & 932 \\
$<1.3 \mathrm{~mm}$ & $48.1 \%$ & 727 \\
$<1.2 \mathrm{~mm}$ & $34.8 \%$ & 526 \\
$<1.1 \mathrm{~mm}$ & $19.6 \%$ & 296 \\
$<1.0 \mathrm{~mm}$ & $12.5 \%$ & 189 \\
\hline
\end{tabular}

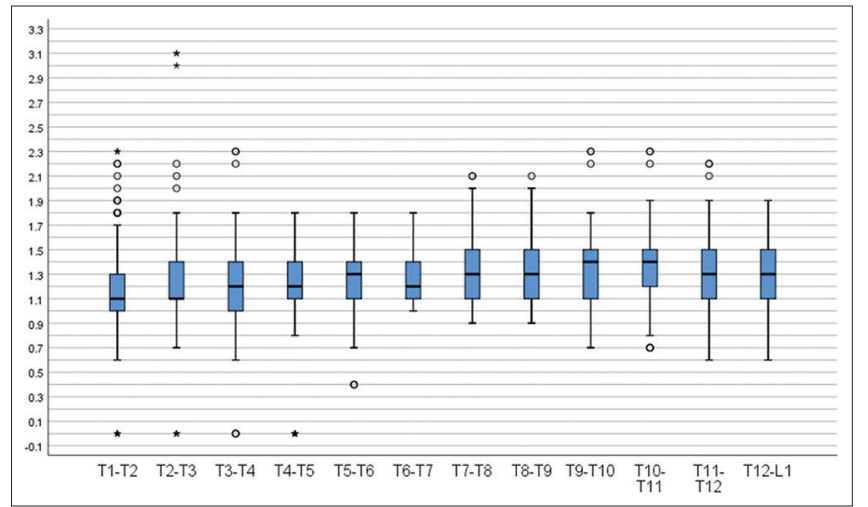

Figure 2: Box plot distribution for individual facet joint levels in the overall sample

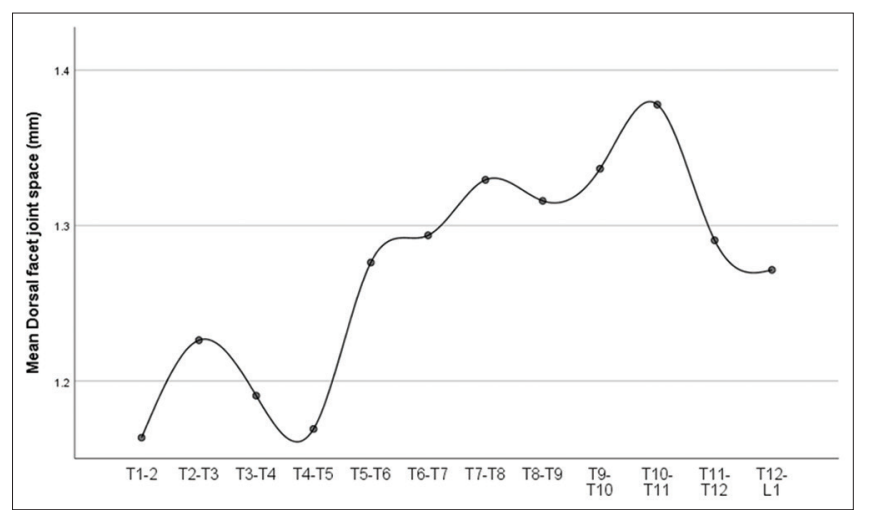

Figure 3: Means of dorsal facet joint space at individual levels in the overall sample

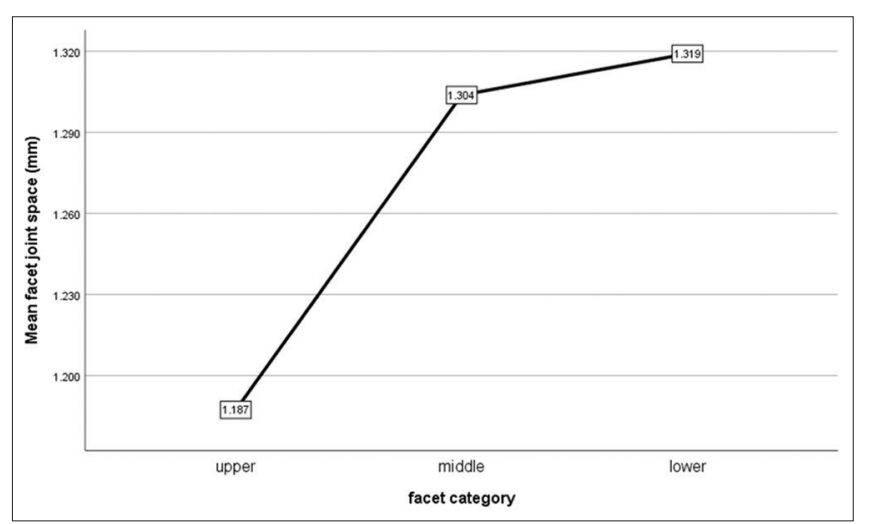

Figure 4: Comparison of facet joint space at upper, middle and lower thoracic levels

Table 5: Descriptive data of facet joint space at individual levels in asymptomatic subjects

\begin{tabular}{lcccccccccccc}
\hline & $T_{1-2}$ & $T_{2-3}$ & $T_{3-4}$ & $T_{4-5}$ & $T_{5-6}$ & $T_{6-7}$ & $T_{7-8}$ & $T_{8-9}$ & $T_{9-10}$ & $T_{10-11}$ & $T_{11-12}$ & $T_{12}-L_{1}$ \\
\hline Mean (mm) & 1.183 & 1.265 & 1.187 & 1.011 & 1.239 & 1.364 & 1.404 & 1.411 & 1.398 & 1.470 & 1.306 & 1.311 \\
SD (mm) & 0.5230 & 0.5671 & 0.4960 & 0.5023 & 0.2897 & 0.2455 & 0.3215 & 0.2969 & 0.3515 & 0.3248 & 0.3683 & 0.3500 \\
SE (mm) & 0.0712 & 0.0772 & 0.0675 & 0.0684 & 0.0394 & 0.0334 & 0.0438 & 0.044 & 0.0478 & 0.0442 & 0.0501 & 0.0476 \\
Range (mm) & $0-2.3$ & $0-3.1$ & $0-2.3$ & $0-1.7$ & $0.4-1.7$ & $1-1.8$ & $1-2.1$ & $0.9-2.1$ & $0.9-2.3$ & $0.8-2.3$ & $0.6-2.2$ & $0.6-1.9$ \\
50th percentile (mm) & 1.100 & 1.100 & 1.150 & 1.100 & 1.300 & 1.3 & 1.300 & 1.400 & 1.450 & 1.500 & 1.300 & 1.300 \\
Interquartile range (mm) & 0.7 & 0.5 & 0.5 & 0.4 & 0.3 & 0.3 & 0.4 & 0.5 & 0.5 & 0.5 & 0.3 & 0.4 \\
Variance (mm) & 0.273 & 0.322 & 0.246 & 0.252 & 0.084 & 0.060 & 0.103 & 0.088 & 0.124 & 0.106 & 0.136 & 0.123 \\
\hline
\end{tabular}


was 1.595 years and median age was 51 years. Age ranged from 33 to 79 years. A total of 864 dorsal facet joints were measured across all levels in them.

Overall mean thoracic facet joint space in symptomatic participants was measured to be $1.252 \mathrm{~mm} \pm 0.2732 \mathrm{~mm}$, ranging from 0 to $2.2 \mathrm{~mm}$ and a standard error of mean $0.0093 \mathrm{~mm}$ and a variance of $0.075 \mathrm{~mm}$. The median was $1.300 \mathrm{~mm}$.

Descriptive statistics of dorsal facet joint space at individual levels in symptomatic participants is outlined in [Table 6] and trends of mean facet joint according to level is shown in [Figure 6].

$\mathrm{T}_{10-11}$ forms the largest joint space, but the smallest joint space is of $\mathrm{T}_{1-2}$ and not of $\mathrm{T}_{4-5}$ as in previous analysis.

Average facet joint space in males was found to be $1.330 \pm 0.091$ and $1.196 \pm 0.187$ in females. Females were found to have significantly smaller facet joint space compared to males (Mann Whitney $\mathrm{U}$ test $P=0.002$ ). There was no significant correlation between age and average dorsal facet joint space among symptomatic participants (bivariate pearson correlation test, $r=-0.140, P=0.242$ ).

When asymptomatic and symptomatic participants were compared, there was a significant difference in sex distribution between the two groups. $(P=0.005$, Pearson Chi-square value $=7.732$ ).

The two groups (asymptomatic and symptomatic subjects) differed significantly on the basis of age and sex distribution. Means of individual facet joint levels were similar in all but three levels $\left(\mathrm{T}_{4-5^{\prime}}, \mathrm{T}_{8-9}, \mathrm{~T}_{10-11}\right)$ [Table 7].[Figure 7] shows box plot of facet joint distribution among asymptomatic and symptomatic subjects.

\section{Discussion}

Ours is the first study to evaluate the measurements of thoracic facet joint space on computed tomography in asymptomatic and symptomatic participants with thoracic spine pain.

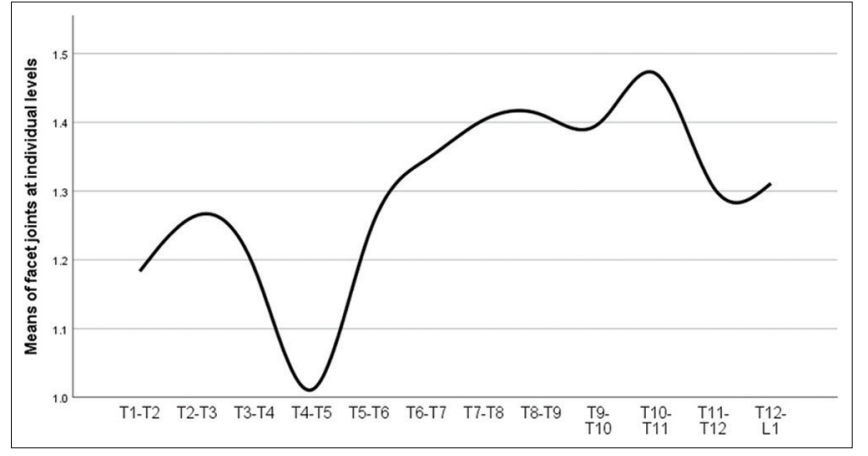

Figure 5: Trend of facet joint space measurement in asymptomatic subjects

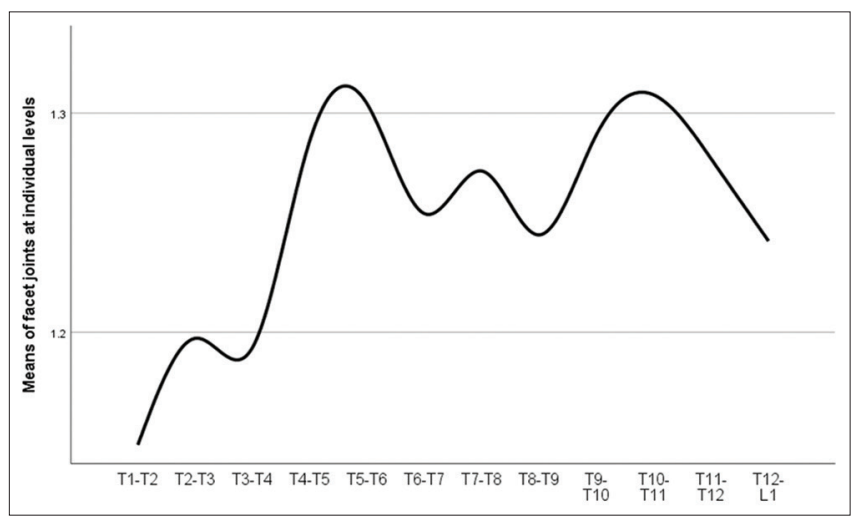

Figure 6: Trend of facet joint space measurement in asymptomatic subjects

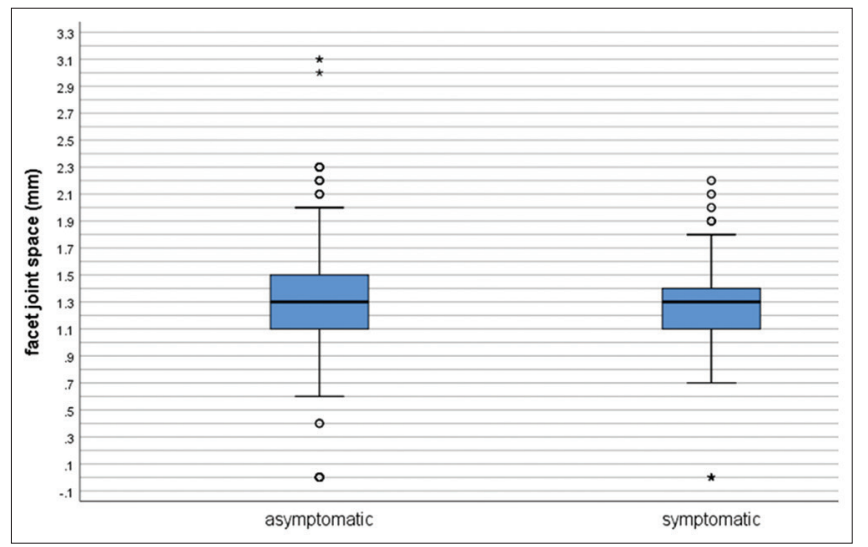

Figure 7: Box plot comparing facet joint measurements in asymptomatic and symptomatic subjects

Table 6: Descriptive data of facet joint space at individual levels in symptomatic subjects

\begin{tabular}{lcccccccccccc}
\hline & $\mathrm{T}_{1-2}$ & $\mathrm{~T}_{2-3}$ & $\mathrm{~T}_{3-4}$ & $\mathrm{~T}_{4-5}$ & $\mathrm{~T}_{5-6}$ & $\mathrm{~T}_{6-7}$ & $\mathrm{~T}_{7-8}$ & $\mathrm{~T}_{8-9}$ & $\mathrm{~T}_{9-10}$ & $\mathrm{~T}_{10-11}$ & $\mathrm{~T}_{11-12}$ & $\mathrm{~T}_{12}-\mathrm{L}_{1}$ \\
\hline Mean (mm) & 1.149 & 1.197 & 1.193 & 1.288 & 1.304 & 1.254 & 1.274 & 1.244 & 1.290 & 1.308 & 1.279 & 1.242 \\
$\mathrm{SD}(\mathrm{mm})$ & 0.3882 & 0.3947 & 0.2440 & 0.2455 & 0.2279 & 0.1768 & 0.2028 & 0.2331 & 0.2759 & 0.2533 & 0.2833 & 0.2324 \\
$\mathrm{SE}(\mathrm{mm})$ & 0.0458 & 0.0465 & 0.0288 & 0.0289 & 0.0269 & 0.0208 & 0.0239 & 0.0275 & 0.0325 & 0.0299 & 0.0334 & 0.0274 \\
Range (mm) & $0-2.2$ & $0-2.2$ & $0.7-1.6$ & $0.9-1.8$ & $0.7-1.8$ & $1-1.6$ & $0.9-1.6$ & $0.9-1.7$ & $0.7-1.7$ & $0.7-1.9$ & $0.8-1.9$ & $0.9-1.7$ \\
S0 $^{\text {th }}$ percentile (mm) & 1.150 & 1.250 & 1.200 & 1.300 & 1.300 & 1.200 & 1.300 & 1.200 & 1.300 & 1.300 & 1.300 & 1.250 \\
Interquartile range (mm) & 0.3 & 0.4 & 0.4 & 0.4 & 0.3 & 0.3 & 0.4 & 0.3 & 0.3 & 0.4 & 0.5 & 0.5 \\
Variance (mm) & 0.151 & 0.156 & 0.060 & 0.060 & 0.052 & 0.031 & 0.041 & 0.054 & 0.076 & 0.064 & 0.080 & 0.054 \\
\hline
\end{tabular}


Overallmean thoracicfacetjoint space of $1.294 \mathrm{~mm} \pm 0.4146 \mathrm{~mm}$ in 648 thoracic facet joints of asymptomatic participants and $1.252 \mathrm{~mm} \pm 0.2732 \mathrm{~mm}$ in 864 thoracic facet joints of symptomatic participants goes against the practice of labelling $<2 \mathrm{~mm}$ joint space as grade $1 \mathrm{FJA}$ in thoracic joints. If we go by this cut-off then $97.8 \%$ of our sample would be classified as having grade 1 thoracic FJA. This is bizarre and worth scrutiny. ${ }^{[22]}$

Over the course of our analysis of dorsal facet joints, we have observed that it is important to assess the facet joint space in both axial and sagittal view rather than on any single view [Figures 8 and 9A, B]. It is easier to visualise facet joint space on sagittal view in dorsal spine because of considerable overlap of facets in axial view. The measurements in sagittal view are more as

Table 7: Comparison between symptomatic and asymptomatic subject

\begin{tabular}{lcccc}
\hline & Mann-Whitney U & Wilcoxon W & $Z$ & $\begin{array}{c}\text { Asymp. } \\
\text { Sig. (2-tailed) }\end{array}$ \\
\hline age & 1288.000 & 3916.000 & -3.238 & 0.001 \\
$\mathrm{~T}_{1-2}$ & 1943.000 & 4571.000 & -0.005 & 0.996 \\
$\mathrm{~T}_{2-3}$ & 1903.500 & 4531.500 & -0.203 & 0.839 \\
$\mathrm{~T}_{3-4}$ & 1911.000 & 3396.000 & -0.164 & 0.870 \\
$\mathrm{~T}_{4-5}$ & 1345.500 & 2830.500 & -2.977 & 0.003 \\
$\mathrm{~T}_{5-6}$ & 1696.500 & 3181.500 & -1.233 & 0.218 \\
$\mathrm{~T}_{6-7}$ & 1561.500 & 4189.500 & -1.912 & 0.056 \\
$\mathrm{~T}_{7-8}$ & 1588.500 & 4216.500 & -1.769 & 0.077 \\
$\mathrm{~T}_{8-9}$ & 1339.500 & 3967.500 & -3.003 & 0.003 \\
$\mathrm{~T}_{9-10}$ & 1600.500 & 4228.500 & -1.705 & 0.088 \\
$\mathrm{~T}_{10-11}$ & 1350.000 & 3978.000 & -2.954 & 0.003 \\
$\mathrm{~T}_{11-12}$ & 1849.500 & 4477.500 & -0.468 & 0.640 \\
$\mathrm{~T}_{12}-\mathrm{L}_{1}$ & 1599.000 & 4227.000 & -1.713 & 0.087 \\
Average & 1852.000 & 4480.000 & -0.454 & 0.650 \\
\hline
\end{tabular}

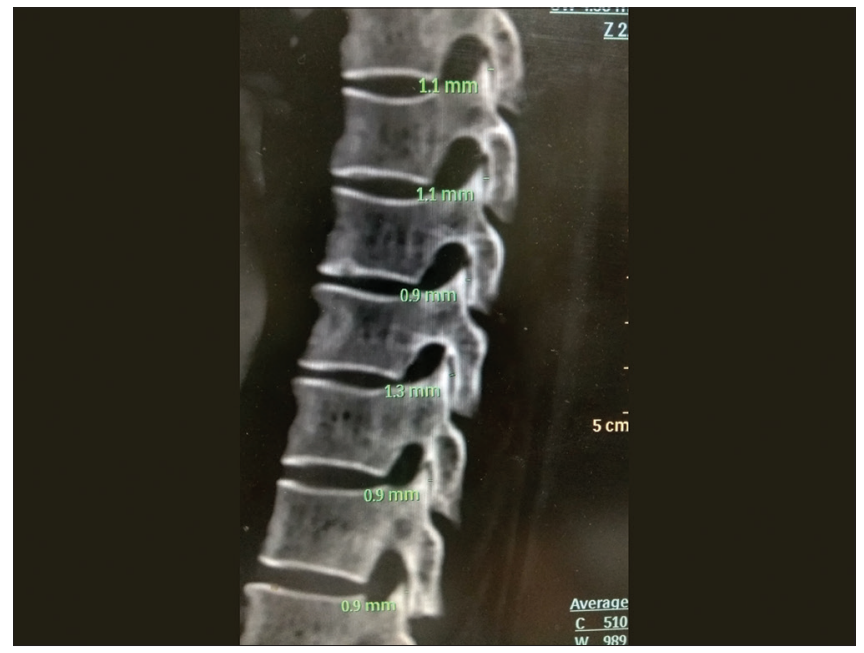

Figure 8: Sagittal CT image (bone window) of 70-year-old female at the level of thoracic facet joints shows facet joint width measured by green coloured calipers in a patient with no history of spinal pain but joint space is $<2 \mathrm{~mm}$ at almost all levels compared to axial view at same level, albeit little but still noticeable.

The 1999 classification of facet joint arthritis by We ishupt et al..$^{[4]}$ was found lacking by us on two accounts.

First, as the grades of FJA increase, the parameter 'decrease in facet joint space' remains a constant. What actually matters is the extent of osteophytes, erosions and other degenerative changes.

Second, this practice of measuring joint space to determine if a facet joint is arthritic is neither time efficient in terms of reporting MRI/CT spine, nor is it supported by literature that decrease in facet joint is of any actual clinical significance.

Most radiologists actually grade the facet joints in terms of degenerative changes rather than measuring the joint space distances in facet joints. Many patients have normal Facet joint spaces accompanied by severe degenerative changes. If such patients are to be kept in grade 3 of FJA based upon the osteophytes then there is no role of decrease in joint space. Similarly, it is not uncommon to see decreased joint space without any degenerative changes.

This cut-off of $2 \mathrm{~mm}$ is arbitrary without taking into account the differences in race, ethnicity, body built, etc.

A review article published by vialle Emiliano neves et al. ${ }^{[23]}$ in 2016 concludes that there is a great disparity in several grading systems involving geometric or descriptive measurements of changes related to disc and facet degeneration in terms of the criteria applied, the results presented, and the possible clinical correlations.

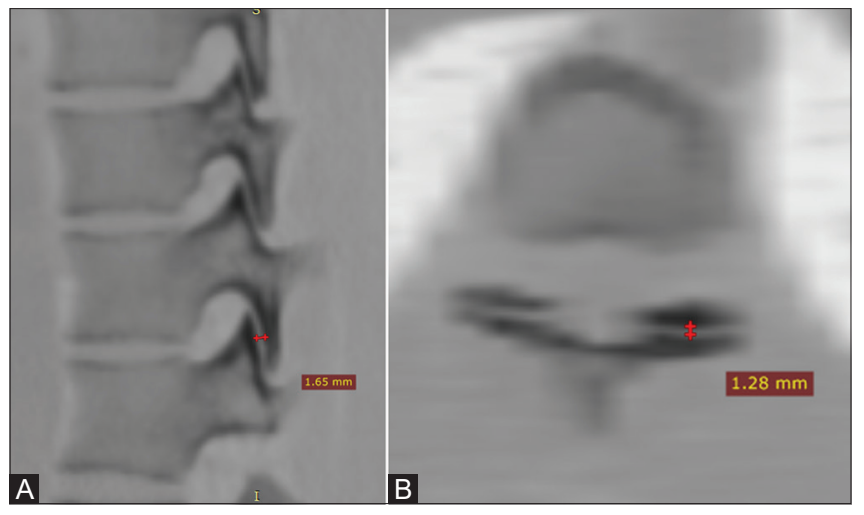

Figure 9 (A and B): (A) CT image (negative bone window) of 28 years old male at the level of D10-11 thoracic facet joints shows difference in facet joint width on sagittal (2A) and axial views (2B) measuring 1.65 $\mathrm{mm}$ and $1.28 \mathrm{~mm}$, respectively. The patient is an asymptomatic young male but joint space at D10-D11 is $<2 \mathrm{~mm}$ which labels it Grade-I FJ arthritis as per existing grading criteria. (B) CT image (negative bone window) of 28-year-old male at the level of D10-11 thoracic facet joints shows difference in facet joint width on sagittal (2A) and axial views (2B) measuring $1.65 \mathrm{~mm}$ and $1.28 \mathrm{~mm}$, respectively. The patient is an asymptomatic young male but joint space at D10-D11 is $<2 \mathrm{~mm}$ which labels it Grade-I FJ arthritis as per existing grading criteria 
The 2-4 mm normal joint space width criteria was initially not mentioned by Pathria et al. ${ }^{\left[{ }^{[5} I t\right.}$ was added later on by Weishupt et al..$^{[4]}$ in 1999 citing Houghton ${ }^{[24]}$ presuming it to be representative of the thickness of two cartilaginous layers. Both the studies included only those patients who had backache.

After the publication of this study further development in research has taken place. In a cadaveric study in 1999 Shepherd et al. ${ }^{[25]}$ demonstrated that the mean cartilage thickness of the knee was significantly greater than that of the ankle and hip $(P<0.001)$.The cartilage thickness is not same in all persons and even in each individual it is different in various joints. They concluded that the larger and heavier was a donor the thicker was the cartilage in the lower limb joints.

Another cadaveric study by Yoganandan et al..$^{[26]}$ in 2003 have demonstrated that the cartilage thickness was lower in females than in males in both upper as well as lower cervical spine. Even more important observation was that the facet joint width demonstrated differences between the Upper Cervical Spine and Lower Cervical Spine $(P<0.0001)$, with higher magnitudes in the upper $(17.4 \mathrm{~mm} \pm 0.4)$ than in the lower $(11.3 \mathrm{~mm} \pm 0.3)$ region. Our own findings concur with this study as we too observed that females have significantly smaller facet joint space compared to males.

Unfortunately, no similar cadaveric or radiological study regarding thoracic facet cartilage thickness or facet joint space could be found in literature as a reference. Chua and Bogduk had reported as early as 1995 that the thoracic medial branches are not that close to the facet joint, as they swing laterally to circumvent the multifidus and at the mid thoracic levels they do not run on bone, instead, they are suspended in the inter-transverse space. ${ }^{[27]}$

A 3-D anatomical and biomechanical analysis of thoraco-lumbar spine was published by Masharawiet al. ${ }^{[28]}$ in which they have concluded that asymmetry in facet orientation is a normal characteristic in thorax.

Further, in a cadaveric micro-CT and sheet plastination study done by Thorpe Lowis CG et al. ${ }^{[29]}$ to know the anatomy and configuration of Facet Joint recesses at different levels of the spine, it was found that in the thoracic region the $\mathrm{FJ}$ recesses were comparatively smaller in size.

In the absence of availability of any separate classification, most of the radiologists use the cut-off of $2 \mathrm{~mm}$ facet joint space to differentiate between grade 0 and grade 1 FJA in thoracic spine too. However, this does not do any justice as the thoracic vertebral and facet joint parameters are not same as that of lumbar vertebra.
Why so much hue and cry about normal facet joint space parameters in thoracic spine?

Thoracic Facet joint arthritis is classified as M46.94 under International classification of diseases ${ }^{[30]}$ (ICD)- 10 and the patients are allowed to file for worker's compensation as per law.

It may be quite normal for a radiologist to report grade 1 FJA if the facet joint space appears decreased to him/her in cases undergoing cross sectional imaging for backache. This is inconsequential, clinically, in most of the cases because such grade 1 Facet Joint Arthritis ought to be managed conservatively. However, the problem in these "harmless" observations in reporting of thoracic spine arises when the patient files for workman's compensation for his arthritis of spine.

This finding of grade1FJA leads to many non-invasive/invasive interventions which are unwarranted. This occurs specially in those cases where no other positive finding corresponding to the complaint of pain in dorsal spine. Why this modification in cut-off value is important is because labelling the facet joints as arthritic may lead to the patient being subject to interventional procedure when no other obvious cause of backache like Prolapsed inter-vertebral disc (PIVD), Nerve root compression can be demonstrated.

Whether the radiologically evident FJA is associated with backache is still a matter of debate.

The casual approach should be replaced by due diligence before labelling a thoracic facet joint being arthritic. This finding can have a bearing upon the implant development in the treatment modality of distraction of facets with intra-articular spacers. ${ }^{[31]}$ Size of spacers used in lumbar spine range from $2.5 \mathrm{~mm}$ to $4 \mathrm{~mm}$ height. The restoration of more than natural facet joint space width may result in over-distraction ultimately affecting the outcome of procedure.

Although futuristic, the work on regeneration of facet via tissue engineering has already begun. ${ }^{[32]}$ Knowledge of anatomical details is a prerequisite for success of such endeavours.

We expect our paper to be an index study to stimulate further research with even larger study samples and better statistical tools to further delineate the normal and abnormal facet joints in largely ignored thoracic part of spine.

\section{Weakness of study}

This study is not without limitations. Major shortcoming of this study is that we have not done this study with medial branch block injections to test or confirm thoracic FJA. Our study is basedupon only radiological findings. The participant was taken as symptomatic or asymptomatic depending on their positive response to dorsal spinal pain 
query. Problem is that though radiologically FJA may be present at any single specific level and the patient may be symptomatic as well but it is not necessary that pain can be attributed to the radiological FJA level. Situation is further complex in case of FJA at multiple levels.

These objections can be addressed to a large extent by diagnostic median branch block.

Another limitation is that it is a CT based study and CT is not the tool to assess the cartilage and early arthritic changes like inflammation and oedema. Last, most of the study participants belong to sub Himalayan farming community. The race, demography, and lifestyle may have influenced our findings as compared to other populations.

\section{Conclusion}

In our study we conclude that the mean of facet joint space in dorsal spine is $1.270 \mathrm{~mm} \pm 0.3416 \mathrm{~mm}$. The popular lumbar FJA classification by Weishupt et al. ${ }^{[4]}$ cannot be applied in its present form in dorsal spine, without the modification in parameters of grade 1 FJA.

\section{Learning points}

- Dedicated cadaveric studies need to be conducted focussing on cartilage thickness and facet joint space of thoracic vertebrae.

- Sagittal section evaluation of dorsal facet joint cannot be omitted.

- Based on our CT based analysis, the $2-4 \mathrm{~mm}$ normal facet joint space does not hold true for thoracic facet joints.

- The lower cut-off of normal dorsal facet joint space probably lies around $1 \mathrm{~mm}$.

\section{Declaration of patient consent}

The authors certify that they have obtained all appropriate patient consent forms. In the form the patient(s) has/have given his/her/their consent for his/her/their images and other clinical information to be reported in the journal. The patients understand that their names and initials will not be published and due efforts will be made to conceal their identity, but anonymity cannot be guaranteed.

\section{Acknowledgement}

We acknowledge the help of our post graduate students Dr Utkarsh Singh, Dr Emad Ansari and Dr Vaibhav Bhandari who helped in data collection and record keeping.We would also like to thank all the participants of this study who spared some time to complete the questionnaires and without whose co-operation this study could not have been completed. Lastly, the role of our secretary Mrs K. K was indispensable throughout the study.

\section{Financial support and sponsorship}

Nil.

\section{Conflicts of interest}

There are no conflicts of interest.

\section{References}

1. Jensen MC, Brant-Zawadzki MN, Obuchowski N, Modic MT, Malkasian D, Ross JS. Magnetic resonance imaging of the lumbar spine in people without back pain. N Engl J Med 1994;331:69-73.

2. Lurie JD, Birkmeyer NJ, Weinstein JN. Rates of advanced spinal imaging and spine surgery. Spine (Phila Pa 1976) 2003;28:616-20.

3. Weiner DK, Kim YS, Bonino P, Wang T. Low back pain in older adults: Are we utilizing healthcare resources wisely? Pain Med 2006;7:143-50.

4. Weishaupt D, Zanetti M, Boos N, Hodler J. MR imaging and $\mathrm{CT}$ in osteoarthritis of the lumbar facet joints. Skeletal Radiol 1999;28:215-9.

5. Pathria M, Sartoris DJ, Resnick D. Osteoarthritis of the facet joints: Accuracy of oblique radiographic assessment. Radiology 1987;164:227-30.

6. SnellRS.The Back. Clinical Anatomy by Regions. $8^{\text {th }}$ ed. New Delhi: Wolters Kluwer Health Publishers; 2008. p. 855.

7. Niemeläinen R, Videman T, Battié MC. Prevalence and characteristics of upper or mid-back pain in Finnish men. Spine (Phila Pa 1976) 2006;31:1846-9.

8. Briggs AM, Smith AJ, Straker LM, Bragge P. Thoracic spine pain in the general population: Prevalence, incidence and associated factors in children, adolescents and adults. A systematic review. BMC MusculoskeletDisord 2009;10:77.

9. Manchikanti L, Boswell MV, Singh V, Pampati V, Damron KS, Beyer CD. Prevalence of facet joint pain in chronic spinal pain of cervical, thoracic, and lumbar regions.BMC MusculoskeletDisord2004;5:15.

10. ChopraP.Chapter 26 - Thoracic pain. In: Smith HS, editor. Current Therapy in Pain.W.B. Saunders; 2009.p. 194-201, ISBN 9781416048367, https://doi.org/10.1016/B978-1-4160-4836-7.00026-2. Available from: http://www.sciencedirect.com/science/article/pii/ B9781416048367000262.

11. Boswell MV, Manchikanti L, Kaye AD, Bakshi S, Gharibo CG, Gupta S, et al. A best-evidence systematic appraisal of the diagnostic accuracy and utility of facet (Zygapophysial) joint injections in chronic spinal pain.Pain Physician 2015;18:E497-533.

12. PiracciniE, ByrneH, CalliM, MaitanS.High abdominal wall pain: An unusual radiation in thoracic facet joint syndrome.Pain Med2017;18:1603-4.

13. Dreyfuss P, Tibiletti C, Dreyer SJ. Thoracic zygapophyseal joint pain patterns. A study in normal volunteers.Spine (Phila Pa 1976) 1994;19:807-11.

14. Laslett M, McDonald B, Aprill CN, Tropp H, Oberg B. Clinical predictors of screening lumbar zygapophyseal joint blocks: Development of clinical prediction rules. Spine J 2006;6:370-9.

15. Schwarzer AC, Wang SC, O'Driscoll D, Harrington T, Bogduk N, Laurent $\mathrm{R}$. The ability of computed tomography to identify a painful zygapophysial joint in patients with chronic low back pain. Spine (Phila Pa 1976) 1995;20:907-12.

16. Zhou X, Liu Y, Zhou S, Fu XX, Yu XL, Fu CL, et al. The correlation between radiographic and pathologic grading of lumbar facet joint degeneration. BMC Med Imaging 2016;16:27.

17. Kim JH, Sharan A, Cho W, Emam M, Hagen M, Kim SY. The prevalence of asymptomatic cervical and lumbar facet arthropathy: A computed tomography study. Asian Spine J 2019;13:417-22.

18. Tiwari P, Kaur H, Kaur H, Jha V, Singh N, Ashraf A. Prevalence of facet joint arthritis and its association with spinal pain in mountain population - A cross-sectional study. J Craniovertebr Junction Spine 2020;11:36-45. 
19. Manchikanti L, Pampati V, Fellows B, Bakhit CE. The diagnostic validity and therapeutic value of lumbar facet joint nerve blocks with or without adjuvant agents. Curr Rev Pain 2000;4:337-44.

20. Schwarzer AC, Aprill CN, Derby R, Fortin J, Kine G, Bogduk N. The false-positive rate of uncontrolled diagnostic blocks of the lumbar zygapophysial joints. Pain 1994;58:195-200.

21. Hinkle DE, Wiersma W, Jurs SG. Applied Statistics for the Behavioural Sciences. $5^{\text {th }}$ ed. Boston: Houghton Mifflin; 2003.

22. Whyte MB, Kelly P. The normal range: It is not normal and it is not a range. Postgrad Med J 2018;94:613-6.

23. Vialle EN, Vialle LRG, Simões CE, de Souza Menegaz P. Clinicalradiographic correlation of degenerative changes of the spine Systematic review. Columna2016;15:325-9.

24. Haughton V. Imaging techniques in intraspinal diseases. In: Resnick D, editor. Diagnosis of Bone and Joint Disorders. Philadelphia: Saunders; 1995. p. 237-76.

25. Shepherd DET, Seedhom BB. Thickness of human articular cartilage in joints of the lower limb. AnnRheum Dis 1999;58:27-34.

26. Yoganandan N, Knowles SA, Maiman DJ, Pintar FA. Anatomic study of the morphology of human cervical facet joint. Spine (Phila Pa 1976) 2003;28:2317-23.
27. Chua WH, Bogduk N. The surgical anatomy ofthoracic facet denervation. ActaNeurochir 1995;136:140-4.

28. Masharawi Y, Rothschild B, Dar G, Peleg S, Robinson D, Been E, et al. Facet orientation in the thoracolumbar spine: Three dimensional anatomic and biomechanical analysis. Spine (Phila Pa 1976) 2004;29:1755-63.

29. Thorpe Lowis CG, Xu Z, Zhang M. Visualisation of facet joint recesses of the cadaveric spine: Amicro-CT and sheet plastination study. BMJ Open Sport Exerc Med 2018;4:e000338.

30. World Health Organization. ICD-10: International Statistical Classification of Diseases and Related Health Problems: Tenth Revision. $2^{\text {nd }}$ ed. World Health Organization; 2004.

31. Goel A, Shah A, Jadhav M, Nama S. Distraction of facets with intraarticular spacers as treatment for lumbar canal stenosis: Report on a preliminary experience with 21 cases. J Neurosurg Spine 2013;19:672-7.

32. O'Leary SA, Paschos NK, Link JM, Klineberg EO, HuJC, Athanasiou KA. Facet joints of the spine: Structure-function relationships, problems and treatments, and the potential for regeneration. Ann Rev Biomed Eng 2018;20:145-70. 